\title{
ORAL HYGIENE PRACTICES AMONG THE VISUALLY IMPAIRED ADOLESCENTS
}

A.N. Azrina, G. Norzuliza, R. Saub. Oral hygiene practices among the visually impaired adolescents. Annal Dent Univ Malaya 2007; 14: 1-6.

\begin{abstract}
The purpose of this study was to gather information on the oral hygiene behaviour among the visually impaired adolescents. Interview and observation methods were used to collect data. A total of 114 visually impaired adolescents were interviewed and 10 of the interviewees were selected for observation on the actual oral hygiene practices. The mean age of the sample was 16 years old. The sample comprised of $53.5 \%$ female, majority were Malays $(86.8 \%)$ and most of them were from the lower income group. Fifty four percent of the sample had low vision and $45.6 \%$ were blind. All of the participants reported that they brushed their teeth daily and most of them brushed twice a day or more. Flossing $(6.1 \%)$ was not common practice among this group. It was observed that they encountered some difficulties, especially when putting the toothpaste on the toothbrush and also the way that they brushed their teeth could cause detrimental effect to the oral cavity. Thus, they need to be taught on proper oral hygiene care so that they can practice safe oral hygiene care and maintain their own oral health.
\end{abstract}

Key words: visually impaired; oral hygiene practices; oral health survey

\section{INTRODUCTION}

There are many types of disability. Disability is defined as a permanent or long term condition that limits an individual's ability to perform usual tasks (1). Visual impairment is one of them; it is categorized as a sensory impairment.

There are two types of visual disability: low vision (partially blind) and totally blind. The World Health Organization (WHO) in 2002 estimated that globally, more than 161 million people were visually impaired, of whom 124 million people had low vision and 37 million were blind. More than $90 \%$ of the world's visually impaired people came from the developing country (2). In Malaysia, the National Eye Survey (NES) (1996) estimated that 54000 Malaysians were blind and 464000 had low vision (3).

Studies have shown that people with disability, regardless of the type of disability, presented with a
Original Article

A.N. Azrina ${ }^{1}$, G. Norzuliza ${ }^{1}$, R. Saub ${ }^{2}$

${ }^{1}$ Undergraduate Students

${ }^{2}$ Senior Lecturer

Department of Community Dentistry

Faculty of Dentistry

University Malaya

50603, Kuala Lumpur

$\mathrm{Tel}(\mathrm{O})$ : 603- 79674888/4805

Email: roslans@um.edu.my

Corresponding author: Dr Roslan Saub

consistently poorer state of oral hygiene, with various levels of periodontal diseases, higher level of untreated dental caries and greater need for extractions than their normal peers $(4,5,6)$.

The visually impaired people are at a greater risk to develop caries, especially root caries, since they are unable to see an early sign of caries such as discoloration which indicates the disease process (7). A study in Kuwait, however, found that caries experience among the blind was lower as compared to other forms of disabilities (8). Greeley et al (9) reported that caries experience among the partially blind increased with age however the caries experience among the totally blind decreased with age.

A study on a group of blind and sighted Israeli teenagers showed that the periodontal health of the sighted group was better than the blind group. In addition, this study also reported that the blind population had poorer oral hygiene as compared to partially blind which had better oral hygiene and lower rates of periodontal disease (10). In addition, when compared with age, oral hygiene status in a partially sighted improved with increase in age, while the blind became worse with increase in age. This is perhaps due to the partially-sighted people interacting more effectively with their environment than the blind population (9)

The primary factor that influences the periodontal health among the visually impaired person was lack of proper oral hygiene (11). The degree of periodontal disease among this group was higher because of the difficulty to take care of oral hygiene without visual feedback of seeing whether plaque had been removed or gums were bleeding while brushing (7).

This study is aimed to gather information on the oral hygiene practices among the visually impaired adolescent. It is hoped that this study will provide 
some information which can be used to assist the oral health providers in implementing oral health promotion programs among the visually impaired adolescents in order to improve their oral health and maintain it though adulthood.

\section{MATERIAL AND METHOD}

\section{Study area}

The study was conducted in Sekolah Menengah Pendidikan Khas Cacat Penglihatan (SMPK), Setapak, Kuala Lumpur. SMPK caters for those who are diagnosed as having some form of visual problems and it is under the Ministry of Education. This is the only school that provides education up to the high school level for the visually impaired people. Students of this school come from all states around Peninsular Malaysia.

\section{Study design}

This was an oral health survey involving an interview and non-participatory observation.

\section{Target population}

The target population for this study was the visually impaired adolescents, aged between 13 to 20 years old.

\section{Sample}

Students attending the Sekolah Menengah Pendidikan Khas Cacat Penglihatan (SMPK) were taken as the sample of this study. The total number of students in this school was 124 comprising of about $90 \%$ Malays and $10 \%$ of the other ethnic groups. The students were categorized as "blind" or "low vision" based on the school register.

\section{Questionnaire}

The questionnaire was constructed in Bahasa Malaysia. The questionnaire includes: demographic information and information on oral hygiene practices. The questionnaire was pretested on normal adolescents, aged between 13 to 17 years old, since it was difficult to find visually impaired adolescents. This pretest was aimed to check the suitability, simplicity and ease of understanding as well as to estimate the time taken to complete the questionnaire. The pretest was done twice. The second pretest was performed using the questionnaire that had been altered according to the first pretest. The pre-tested questionnaire was used in the actual study.

\section{Data collection}

Permission to carry out the study was obtained from the Ministry of Education and the principal of the school prior to the commencement of the study. A brief explanation about the study was given to the principle by the researchers. Suitable date and time to conduct the study were discussed with the principal of the school. Data was obtained by using two methods: Interview and observation.

\section{Interview:}

A face-to-face interview was conducted using the questionnaire described above. The researchers approached the participant individually during the preparation class in the afternoon. The purpose and procedure of the study was explained to each participant and the participants were asked whether they agree to participate or not. The verbal agreement was considered as consent. Each interview took about 7 minutes to 10 minutes to complete.

\section{Observation:}

Observation on the actual oral hygiene practice was carried out. Each female participant interviewed was asked to participate in this part of the study. The recruitment stopped when ten participants were obtained. This part was to observe how they actually perform the oral hygiene practice. The observation was conducted at the hostel. Since both of the researchers were women, the observation was only performed at the girls' hostel. The participants were asked to brush their teeth. This was recorded using video camera. One researcher (NAA) observed while the other one $(\mathrm{NG})$ recorded the event using the video camera.

\section{Data management and data analysis}

Data collected from the interviews was entered into the computer and was analyzed using SPSS program. Based on the video and the notes taken, the action in performing oral hygiene was described in detail by the researchers.

\section{Confidentiality}

The questionnaire used in this survey was completely anonymous with no means of participant identification. Information obtained from the questionnaire was coded, entered into a SPSS data analysis package and all questionnaires were destroyed after data entry. All information related to the survey was stored in a secure cabinet. This study was approved by the Faculty of Dentistry Ethical Committee, University of Malaya.

\section{RESULTS}

\section{Response rate}

The total number of students in the school was 124. However, $114(91.9 \%)$ of them participated in the interview. Ten of the students were absent during the study period; one of them was away for holiday overseas, one went to the hospital and eight were having co-curriculum activities away from school. 


\section{Characteristics of the sample}

Table 1 shows the socio-demographic characteristics of the sample. The age range was between 13 years old to 20 years old with the mean age was 16 years old. The proportion of male participants was slightly higher than the female; majority was Malays, at $86.8 \%$. Most of them were from the lower income group (59.6\%), where their parents combined incomes were less than RM1000 per month. Slightly more than half of the participants $(54.4 \%)$ were categorized as having low vision.

Table 1. Characteristic of the sample $(n=114)$

\begin{tabular}{lrc}
\hline Characteristic & $\mathrm{n}$ & $\%$ \\
\hline Gender & & \\
Male & 61 & 53.5 \\
Female & 53 & 46.5 \\
Total & 114 & 100.00 \\
& & \\
Ethnicity & & \\
Malay & 99 & 86.8 \\
Chinese & 9 & 7.9 \\
Indian & 5 & 4.4 \\
Others & 1 & 0.9 \\
Total & 114 & 100.00 \\
& & \\
Family income & & \\
<RM1000 & 68 & 59.6 \\
RM1000-RM300 & 35 & 30.7 \\
>RM3000 & 6 & 5.3 \\
Other/don't know & 5 & 4.4 \\
Total & 114 & 100.00 \\
\hline
\end{tabular}

\section{Oral Hygiene Behaviour}

\section{Interview Finding}

All respondents reported that they clean their teeth using toothbrush and toothpaste. Only a small proportion of them used floss $(6.1 \%)$, about $15 \%$ used toothpicks and $22 \%$ used mouthwash for rinsing (Table 2).

Tooth brushing behaviour: Half of the participants reported that they brushed their teeth twice a day, in which the percentage of male participants was higher than female (Table 3). When the participants were asked about the usage of fluoridated toothpaste, half of them claimed that

Table 2. Equipment used for mouth cleaning

\begin{tabular}{lrr}
\hline Equipments & $\mathrm{N}$ & \multicolumn{1}{c}{$\%$} \\
\hline Toothbrush & 114 & 100.0 \\
Toothpaste & 114 & 100.0 \\
Floss & 7 & 6.1 \\
Tooth pick & 17 & 14.9 \\
Mouth wash & 25 & 21.9 \\
\hline
\end{tabular}

they used fluoridated toothpaste while the other half of the participants did not know whether their toothpaste contained fluoride. Almost 30 percent of the participants changed their toothbrush in less than 3 months time, where the proportions of male participants were almost twice than the female participants (Table 3). About 20.2 percent of the participants reported that they were not sure as to how often they changed their toothbrush.

Flossing behaviour: Only a small proportion of the participants used floss, which was about 6.1 percent. Among those who used floss, 2.6 percent of them used daily and all were females (Table 3 ).

\section{Observation Finding}

The actual oral hygiene practice was observed on ten of the female participants. Three of them were having low vision and seven were blind. From the observation, it was observed that most of them used straight handle and large headed toothbrush. Two of them were using toothbrush which were damaged where the bristles had splayed. All of them used fluoridated toothpaste.

Generally, the most obvious difficulty encountered during tooth brushing were putting toothpaste on the toothbrush. For the low vision participants they had to bring their tooth brush

Table 3. Response on oral hygiene behaviour

\begin{tabular}{cccc}
\hline & Male & Female & Total \\
Oral hygiene behaviours & $(\mathrm{N}=61)$ & $(\mathrm{N}=53)$ & $(\mathrm{N}=114)$ \\
& $\mathrm{n}(\%)$ & $\mathrm{n}(\%)$ & $\mathrm{n}(\%)$ \\
\hline
\end{tabular}

\section{Toothbrushing:}

Frequency of brushing per day

$\begin{array}{lrrr}\text { Once or less } & 9(14.8) & 6(11.3) & 15(13.2) \\ \text { Twice } & 33(54.1) & 24(45.3) & 57(50.0) \\ 3 \text { times or more } & 19(31.1) & 23(43.4) & 42(36.8) \\ & & & \\ \text { se fluoridated toothpaste } & & & \\ \text { Yes } & 27(44.3) & 29(54.7) & 56(49.1) \\ \text { No } & 4(6.6) & 0 & (0.0) \\ \text { Don't know } & 30(49.1) & 24(45.3) & 54(47.4)\end{array}$

Frequency of changing toothbrush

$\begin{array}{lrrr}<3 \text { month } & 22(36.0) & 12(22.6) & 34(29.8) \\ 3 \text { month } & 8(13.1) & 11(20.8) & 19(16.7) \\ \text { After 3 month } & 22(36.1) & 16(30.2) & 38(33.3) \\ \text { Not sure } & 9(14.8) & 14(26.4) & 23(20.2)\end{array}$

\section{Flossing}

Frequency of flossing

Daily

Seldom

$\begin{array}{llllll}0 & (0.0) & 3 & (5.7) & 3 & (2.6)\end{array}$

Not Flossing

2 (3.3) 2 (3.8) 4 (3.6)

59 (96.7) $48(90.5) \quad 107(93.8)$

\section{Rinsing}

Rinsing after meal

$\begin{array}{lrrr}\text { Yes } & 36(59.0) & 33(62.3) & 69(60.5) \\ \text { Seldom } & 17(27.9) & 12(22.6) & 29(25.4) \\ \text { No } & 8(13.1) & 8(15.1) & 16(14.1)\end{array}$


really close to their eyes prior to the placement of toothpaste. (Picture 1)

Meanwhile for the blind participants, they tended to hold the head of the tooth brush with their thumb and index finger as a reference to put the toothpaste on the surface of bristles (Picture 2). They then used their fingertip to spread the toothpaste along the surface of the bristles. However, some of them (6 out of 10) did not realize that the toothpaste that they put on the toothbrush had dropped out or it was too little (not even a pea size). One participant had used her finger to spread the toothpaste directly onto the teeth surfaces, instead of putting it onto the toothbrush before brushing.

It was observed that all ten participants were not brushing their teeth systematically, where some of the surfaces were not brushed. Most of them brushed ( 9 out 10 ) their teeth horizontally especially on the posterior and inner surfaces. One of the blind participants brushed the anterior teeth vertically (Picture 3). Three of them used both hands to brush their teeth, where they used their left hand to brush the teeth on the left side and vice versa. Three of the blind participants applied forceful pressure during the strokes and were brushing too fast. It was noticed that the gums of some of them were bleeding during brushing.

\section{DISCUSSION}

This study provides an insight into the practices and difficulties encountered by the visually impaired population in performing oral hygiene practices.

All of the participants in this study reported that they brushed their teeth daily using toothpaste. Majority of them brushed their teeth twice a day or more. The frequency of brushing teeth were similar to the normal population as reported by Esa et al (12) where majority of Malaysian adults aged 15-24 brushed their teeth daily and did it twice a day or more.

Although all of the participants use toothpaste during brushing, almost half of the participants were not aware whether their toothpaste contains fluoride or not. It is not surprising since they are not able to read the label of the toothpaste. Even in the normal population many reported that they are not aware whether their toothpaste contains fluoride or not as reported by Esa et al (12). It may also be possible that they are not aware of the importance of fluoride in preventing caries. If that is the case, they must be informed about the beneficial effect of fluoride either through dental health education or by including it into the school curriculum (13).

The effectiveness of brushing also depends on the state of the toothbrush (14). As a general rule, it is recommended that the toothbrush need to be changed every three months time (15). However, this

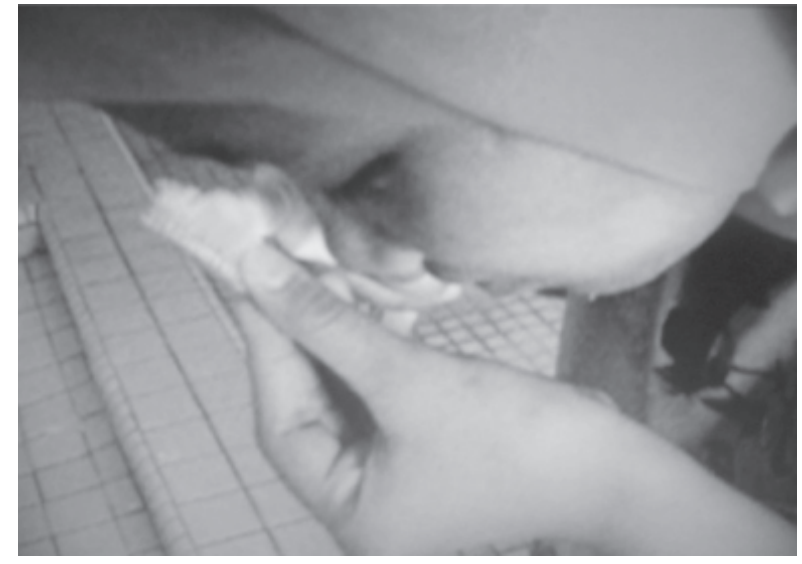

Picture 1: Shows the low vision participant bringing the tooth brush really close to the eyes when putting the toothpaste.

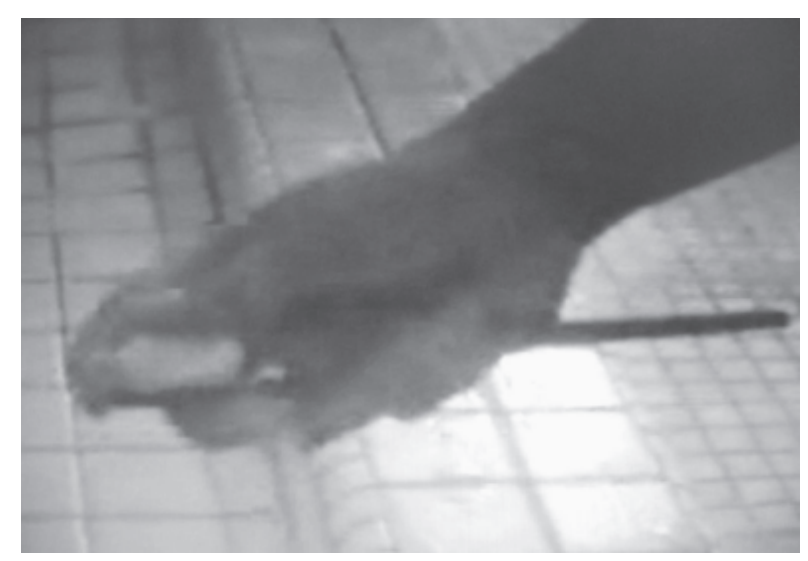

Picture 2: Shows the participant holding the head of the toothbrush with her thumb and index finger to put on the toothpaste.

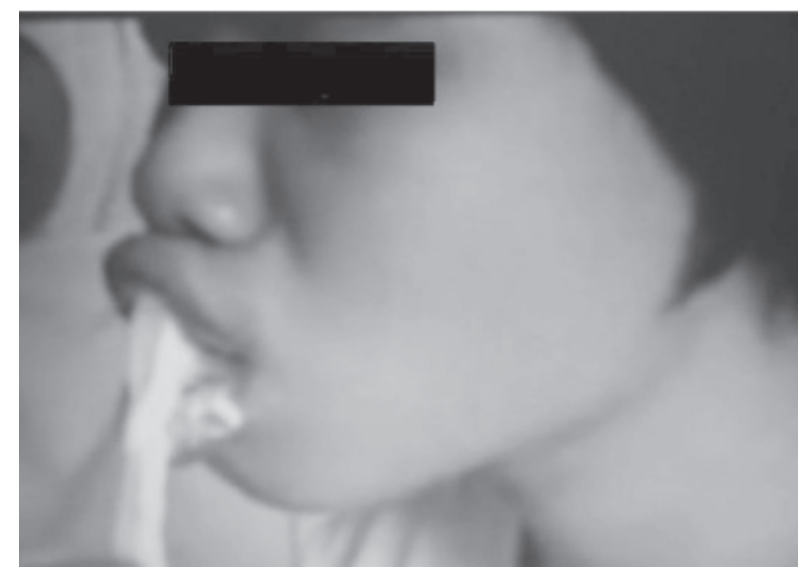

Picture 3: Shows the participant brushing the anterior teeth vertically.

estimate can vary due to the differences in brushing habit as well as the quality of the brush itself. Almost $30 \%$ of the participants surveyed reported that they replaced their toothbrush in less than 3 months. However, this study did not ask the reason of why were they replacing it very frequently. 
According to Harris et al (15), if the toothbrushes need to be replaced more frequently than every three months due to toothbrush wear, then the patient's brushing technique should be checked. This is because toothbrush wear is influenced more by brushing methods than other factors such as frequency of brushing (15).

From the observation on the actual oral hygiene practice, there were participants that were using toothbrush which were damaged where the bristles had splayed. Bad condition of toothbrush will not only affect the efficiency of brushing but it can also cause trauma to the soft tissue of the mouth. Thus, the blind people must be informed on when they need to change their toothbrush.

The use of force is not needed to remove plaque. Brushing should be done gently to avoid any injury to the surrounding tissues. However, it was observed that some of the participants, especially the blind, applied a forceful pressure during the strokes and they were brushing too fast. Therefore, a proper guidance on the amount of force requires while brushing must be taught to this group of population.

Unlike tooth brushing, flossing is an uncommon oral hygiene practice even in the normal population as reported by Esa et al (12). This is perhaps due to the cost, availability or its alien cultural origin (16). Esa et al (12) suggested that one way to overcome this problem is to include education on dental flossing as part of the routine dental health education. The importance of flossing as an interdental aid should be emphasized in delivering dental health education. This is important due to fact that tooth brushing alone has a limited effect in removing interdental plaque (10). Thus, it is a challenge to the health promoters in educating the visually impaired people as they are not able to learn by visual imitation.

It is recommended that a proper oral hygine care needs to be taught to this group of population. Hoverver, there need to be an awareness that the blind people cannot learn by visual imitation of the dentist's homecare demonstration. Instead, they are accustomed to follow verbal instructions more effectively. A greater reliance must be placed on tactile stimuli, such as teaching the visually impaired person to detect plaque with the tongue (7) Therefore, to educate the visually impaired people a clear verbal instruction and acting out by touch have to be used (17).

\section{REFERENCES}

1. Nelson DM, Barker G, Bray KK. Special Needs Patient Care. In Nelson DM (ED). Review of Dental Hygiene. Philadelphia, W.B Saunders Company 2000; pp. 503-41.
2. World Health Organization. International statistical classification of disease, injuries and causes of death. Tenth Revision. Geneva, WHO: 1993.

3. Zainal M, Ismail SM, Ropilah AR, Elias H, Arumugam G, Alias D, Fathilah J, Lim TO, Ding LM, Goh PP. Prevalence of blindness and low vision in Malaysian population: results from the National Eye Survey 1996. Br J Opthalmol 2002; 86: 951-6.

4. Hulland S., Sigal M.J. Hospital-based dental care for persons with disabilities: a study of patient selection criteria. Special Care in Dentistry 2000; 20: 131-8.

5. Nunn JH, Murray JJ. The dental health of handicapped children in Newcastle and Northumberland. British Dental Journal 1987; 162: 9-14.

6. Nowak AJ. Dental disease in handicapped persons. Special Care in Dentistry 1984; 4: 669.

7. Schembri A, Fiske J. The implications of visual impairment in an elderly population in recognizing oral disease and maintaining oral health. Special Care Dentist 2001; 21: 222-6.

8. Shyama M., Al-Mutawa SA, Morris RE, Sugathan T, Honkala E. Dental caries experiences of disabled children and young adults in Kuwait. Community Dental Health 2001; 18: 181-6.

9. Greeley CB, Golstein PA, Forrester DJ. Oral manifestation in group of blind students. Journal of Dentistry for Children 1976; 43: 39-41.

10. Anaise Z.J. Periodontal disease and oral hygiene in a group of blind and sighted Israeli teenagers (14-17 years of age). Community Dent Oral Epidemiology 1979; 7: 353-6.

11. Mann J, Wolnerman JS, Lavie G, Carlin Y, Garfunkel AA. Periodontal treatment needs and oral hygiene for institutionalized individuals with handicapping condition. Special Care in Dentistry 1984; 4: 173-6.

12. Esa R, Razak I, Jalalludin RL, Jaafar N. A survey on oral hygiene practices among Malaysian adults. Clinical Preventive Dentistry 1992; 14: 23-7. 
13. Natar A.M. Oral Health and related behaviour of 16 year old school children in Sarawak. University of Malaya, 2000. MCD thesis.

14. Selamat N. Oral health status and practices among factory workers. University of Malaya, 2003. MCD thesis.

15. Harris No, Garcia-Godoy. Primary Preventive Dentistry. $6^{\text {th }}$ Edition. New Jersey: Pearson Practice Hall. 2004.
16. Jaafar N. Oral health behaviour in a multi-ethnic society. Monograph of Paper presented at the "Symposium on developing methods to assess cultural dimensions of oral health and disease." International Association for Dental Research Scientific Meeting, Westin Plaza Hotel, Singapore 1995.

17. Lebowitz EJ. An introduction to dentistry for the blind. Dental Clinics of North America 1974; 18: 651-69. 